\title{
Correction to "Association of Speculum Lubrication with Pain and Papanicolaou Test Accuracy"
}

In the abovementioned article, ${ }^{1}$ there was an error in the Results section of the Abstract. The Results section notes that "For premenopausal women, lubricant gel use significantly reduced the pain scores of the participants $(P<.05)$." This is incorrect and it should read: "For postmenopausal women, lubricant gel use significantly reduced the pain scores of the participants $(P<.05)$." The electronic version on the Journal of the American Board of Family Medicine website has been corrected. We apologize for the error, and we regret any confusion or inconvenience it may have caused.

(doi: 10.3122/jabfm.2013.01.120304.)

\section{Reference}

1. Uygur D, Guler T, Yayci E, Atacag T, Comunoglu C, Kuzey GM. Association of speculum lubrication with pain and Papanicolaou test accuracy. J Am Board Fam Med 2012;25:798-804. 